\title{
Arno Burkholder, La red de los espejos. Una historia del diario Excélsior, 1916-1976. Ciudad de México: Fondo de Cultura Económica, 2016.
}

DOI: https://doi.org/10.15648/hc.38.2021.2823

Los análisis históricos sobre la prensa como objeto de estudio han aumentado en los últimos años. La mayor parte se refiere a las actividades de los impresos y su peso específico en el espacio público, entre el período de la Independencia y los inicios del siglo XX. Sin embargo, los trabajos sobre los diarios modernos de distribución masiva aún son escasos, por lo que resulta de interés la obra de Arno Burkholder sobre Excélsior de México, que lo examina en tres ámbitos: como empresa, como periódico y como actor político.

Sus fuentes primarias son los periódicos de la época y las entrevistas a diversos actores relacionados con el impreso. La narración, de tipo cronológico, se divide en cuatro capítulos que dan cuenta de la trayectoria institucional. El primero se refiere al contexto, el perfil del fundador, los periodistas que participaron en el proyecto inicial, así como aspectos de su funcionamiento (línea editorial, público objetivo, prensa, publicidad, entre otros). También se explica la cercana relación de su propietario, Rafael Alducin, con los gobiernos de turno y la inestabilidad de la empresa desde la muerte de su dueño, que luego de pocos años terminó en una declaratoria de bancarrota y en su transformación en cooperativa, por solicitud de un grupo de trabajadores del impreso al Estado.

En el capítulo segundo Burkholder describe la estructura cooperativista con la que empezó a funcionar el diario a partir de los años treinta y los conflictos que ese tipo de administración generó, en principio con los sindicatos, a los que el gobierno buscó frenar con esta opción; 
pero sobre todo entre los periodistas, quienes se disputaron el poder al interior del impreso. El Estado, que había entregado recursos para la reconversión del diario, apoyó a los colaboradores directos de Alducin, tanto el ámbito periodístico como en el gerencial. Estos acumularon poder y devinieron en caciques del medio, al que gobernaron durante 30 años; mientras se beneficiaban de las políticas estatales que favorecieron a los grandes diarios: importación de materias primas a bajo costo, acceso a información oficial y pago informal a los reporteros.

Pero a partir de 1962 las cosas cambiaron, pues en menos de un semestre fallecieron el director editorial y el director financiero, dando paso a que dos fracciones rivales del diario, formadas casi en su totalidad por los periodistas que se disputaban su administración, tema que se trata en el capítulo tercero. Finalmente, una nueva generación se hizo cargo del impreso, aunque estuvo encabezada por el último periodista que había trabajado con Alducin, quien para entonces ya tenía 82 años de edad.

En medio de esa crisis interna, el Estado intervino nuevamente para garantizar que Excélsior fuera dirigido de acuerdo a sus intereses. Una vez en el poder, la nueva directiva emprendió acciones para frenar las iniciativas de sus opositores. Los cambios, que se evidenciaron en la presentación del impreso, fueron bien recibidos por el público, pues para 1965 Excélsior tenía un tiraje promedio de 140.000 ejemplares y sostenía una cooperativa con 1.400 integrantes. No obstante, en 1968 falleció el director y se agudizaron los problemas internos.

En el capítulo final el autor detalla las acciones tomadas por el nuevo director, Julio Scherer, para depurar la Redacción, pero también explica que sus decisiones no lograron terminar con las "igualas" (pagos que recibían los reporteros por los espacios publicitarios que contrataban sus fuentes) ni con los negocios paralelos que los periodistas habían conseguido por sus contactos e influencias. En el ámbito externo, la

308 nueva administración no contó con el apoyo del gobierno, que consideró insuficiente el apoyo del diario durante las manifestaciones estudiantiles de 1968, razón por la cual buscó limitar su capacidad de acción. 
Los conflictos se mantuvieron abiertos hasta 1976, cuando Scherer fue denunciado por el grupo opositor de malos manejos administrativos, lo que llevó a que tanto él como seis miembros de su equipo fueran suspendidos y, posteriormente, expulsados de la cooperativa, al no lograr apoyo interno ni del gobierno. En el epílogo, Burkholder explica que, luego de la expulsión, Scherer y su equipo fundaron el semanario Proceso, referente del periodismo independiente de México para varias generaciones. Mientras tanto, Excélsior pasó a ser dirigido por Regino Díaz Redondo, quien lo dirigió hasta el 2000, cuando fue expulsado por malos manejos económicos; y, en 2006, el diario dejó de ser una cooperativa, al ser comprado por el Grupo Imagen.

Si bien estudios previos habían mostrado que Excélsior, conjuntamente con El Universal, introdujeron en México las prácticas del periodismo moderno, dando paso al diarismo noticioso e informativo y que transformaron el lenguaje de los periódicos desde su condición de productos masivos sometidos a las normas del mercado ${ }^{1}$; el estudio de Burkholder da cuenta de que la toma de distancia de la política partidista no implicó - no podía implicar- una separación de lo político (en el sentido de Rosanvallon), dado que los diarios modernos fueron parte constitutiva de los sistemas de representación del siglo $\mathrm{XX}^{2}$.

No obstante, en la obra de Burkholder se echa de menos un análisis más detenido sobre Excélsior en cuanto actor político, relacionado con el Estado no solo como una empresa que requirió de ayuda económica y mediación en conflictos internos, sino también como medio de comunicación influido por esos problemas internos al momento de difundir información pública sobre los acontecimientos sociales, pues aunque se apuntan algunos datos al respecto no se hace referencia al

1 Varios de estos aspectos han sido señalados por autores como Jesús Timoteo Álvarez y Ascensión Martínez Riaza, Historia de la Prensa Hispanoamericana. (Madrid: MAPFRE, 1992); Ana María Serna, "Periodistas mexicanos: ¿voceros de la nueva Doctrina Monroe?", Estudios Mexicanos Vol. 26 No. 2 (2010): 207-237, http://www.jstor.org/stable/10.1525/msem.2010.26.2.20 2; y Jacqueline Covo, "La prensa en la historiografía mexicana: problemas y perspectivas", Historia Mexicana Vol. 42 No. 3, (1993): 689-710.

2 La diferencia entre "lo político" y "la política" es que en el primer caso se habla de todo aquello que constituye la polis, más allá del campo inmediato de la competencia partidaria por el ejercicio del poder. Pierre Rosanvallon, Por una historia conceptual de lo político. Lección inaugural en el Collége de France. (Buenos Aires: Fondo de Cultura Económica, 2003), 20. 
proceso noticioso como parte de acciones concretas, en el marco de modelos compartidos, relevantes para entender la interacción social ${ }^{3}$.

Para concluir, cabe señalar que si bien la administración cooperativista de Excélsior fue una excepción respecto a la mayoría de grandes diarios latinoamericanos del siglo XX (empresas privadas de propiedad familiar), su línea editorial fue similar en todos los casos: moderadamente pro o antigubernamentales, moderadamente conservadores en temas económicos y moderadamente progresistas en asuntos sociales ${ }^{4}$. Esta visión de conjunto muestra que tuvieron una labor específica en la generación del orden simbólico de las sociedades de la región, en directa relación con las ambigüedades de sus agentes sociales respecto a la democracia, la identidad y la ciudadanía en el marco de Estados generalmente autoritarios, línea de análisis que queda por desarrollarse en futuras investigaciones.

\section{Katerinne Orquera Polanco \\ Universidad Andina Simón Bolívar, Sede Ecuador katerinne.orquera@gmail.com}

3 A la relevancia de estos procesos hace referencia Teun A. Van Dijk en La noticia como discurso. Comprensión, estructura y producción de la información. Barcelona: Paidós, 1990, 201-202.

4 Álvarez y Martínez Riaza, Historia de la Prensa..., 20. 